\title{
Coaxial Circular Jet Flows with Conical Attachments
}

\author{
A.T. INAN ${ }^{a, *}$, M.Z. GUL ${ }^{b}$, M.O. ISIKAN ${ }^{c}$ \\ ${ }^{a}$ Technical Education Faculty, Mechanical Education Department, Marmara University, \\ Göztepe Kampüsü 34722 Istanbul, Turkey \\ ${ }^{b}$ Engineering Faculty, Mechanical Engineering Department, Marmara University, \\ Göztepe Kampüsü 34722 Istanbul, Turkey \\ ${ }^{c}$ Technology Faculty, Mechanical Engineering Department, Marmara University, \\ Göztepe Kampüsü 34722 Istanbul, Turkey
}

\begin{abstract}
This study is devoted to experiments on jet flows, which have many application areas. It shows the obtained jet flow structure. The experiments were carried out in a subsonic sucking wind tunnel having cross-section of $32 \times 32 \mathrm{~cm}^{2}$, length of $75 \mathrm{~cm}$, and turbulence densities of $0.5 \%$. One-channel hot-wire anemometer (HWA) was used in measurements. For circular jet, a steel pipe was used with a length of $120 \mathrm{~cm}$ and a diameter of $8 \mathrm{~mm}$. Air generator was used for generating air into the jet flow and measurements were done at different jet flow velocities. Moreover, a conical diffuser with a length of $21 \mathrm{~cm}$ and $6^{\circ}$ slope was attached to the nozzle exit and effect of this diffuser on jet flow was examined. Seven types of measurement in three different categories were carried out. In experimental studies, velocity and turbulence distribution, axial velocity variation, jet half widths and, using these, jet diffusion rates and angles were measured. Moreover, flow analyses were done by drawing moment and frequency distribution for measurement sensitivity. These experimental results were compared with the studies on jet flow.
\end{abstract}

DOI: 10.12693 /APhysPolA.127.1373

PACS: 47.27.wg, 47.80. Cb

\section{Introduction}

Jet flow is one of the most important subjects, in which main flow structures are investigated, and which has many application areas, such as engine combustion, in laser, in chemical and in drug industries. Many researches have done experimental studies on jet flows. Although the behaviour of this kind of jets is defined for free jets, there are some deficiency, especially on turbulence data, and suitable interaction of jet flows according to starting conditions [1].

Many of the first studies were related to the free jet flow development in the fluid environment. The first detailed study on his subject was done by Trupel [2] in 1915. The first researches studying this subject in more detail using hot wire anemometer are: Reichardth in 1942, Corrsin in 1946 [3], Hinze and Zijnen in 1949 [4], and Albertson et al. in 1950 [5]. Wygnanski and Fiedler showed in 1969 [6] various appearances of free jet turbulence structures and r.m.s. variations of turbulence fluctuation values along the jet axis using hot wire anemometer. Davies and Fisher [7], Bradshaw [8], and Hussein and George [9] have also studied the same subject. Taulbee [10] repeated the study by using LDA (Laser Doppler Anemometry). In these measurements it is seen that circular jet expansion is slower than that of plain jet and isomorphic zone is occurring at the distance of 50-70 times of nozzle diameter. Antonia [11], and Komori and Ueda [12] stud-

* corresponding author; e-mail: ainan@marmara.edu.tr ied experimentally fully developed regions of the circular jets by injecting jet in the same axial flow. Morris and Zaman [13] studied the characteristics of a symmetrical axial jet experimentally and numerically using hot wire anemometer and double component anemometer. They made measurements at the jet outlet and at the axis and estimated the noise level using velocity fluctuations. Sivakumar et al. studied the potential core region of the circular jet using hot wire anemometer [14].

In this study, the frequency analysis was done of measurements at the jet axis. As it is seen in Fig. 1a and in Fig. 1b the frequency distributions at the axis show similarity. In both graphs the peaks of the turbulence movements are seen at the same frequency. The Strouhal number at the exit is found as $S t=0.021$. This number is found to be between 0.013 and 0.023 by many researches. The Strouhal number found in this study also falls in this range.

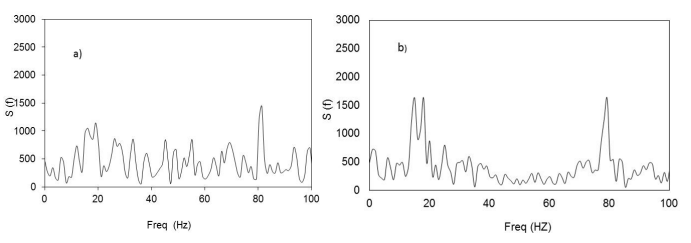

Fig. 1. The frequency distributions of the measurements in type A6, (a) $x / D=0.3$ station, (b) $x / D=$ 12.5 station.

In the last years, the measurements of jet flows using hot wire anemometer have been done by many researches $[6,9,10,15,16,17]$. Jet expansion ratios of jet flow structures, obtained in experimental studies, are given in Table I. 
TABLE I

Comparison of jet expansion ratios of asymmetrical incompressible jets, found by the different researches.

\begin{tabular}{c|c|c|c}
\hline \hline Researchers & Year & $\begin{array}{c}\text { Spreading } \\
\text { ratio }\end{array}$ & $\begin{array}{c}\text { Equipment } \\
\text { type }\end{array}$ \\
\hline Wygunanski, et al. [6] & 1969 & 0.086 & HWA \\
Rodi [15] & 1979 & 0.086 & HWA \\
Capp [16] & 1983 & 0.095 & LDA \\
Panchakesan, et al. [17] & 1986 & 0.096 & Moving HW \\
Taulbee, et al. [10] & 1987 & $0.094-0.102$ & LDA HWA \\
Hussein, et al. [9] & 1989 & 0.094 & Moving HW
\end{tabular}

In this study, velocity changes occurring along the jet axis and jet expansion ratios are presented. As the sensibility of the measurement statistics, the $4^{\text {th }}$ moments of the measurements were calculated and the frequency distributions are shown.

For the case of tunnel velocity of $10 \mathrm{~m} / \mathrm{s}$ and $20 \mathrm{~m} / \mathrm{s}$, the axial velocity changes are presented in Fig. 2 and Fig.3, and the axial velocities are shown in Table II and Table II. As it is seen from the figures, velocity linearly decreases at the axis.

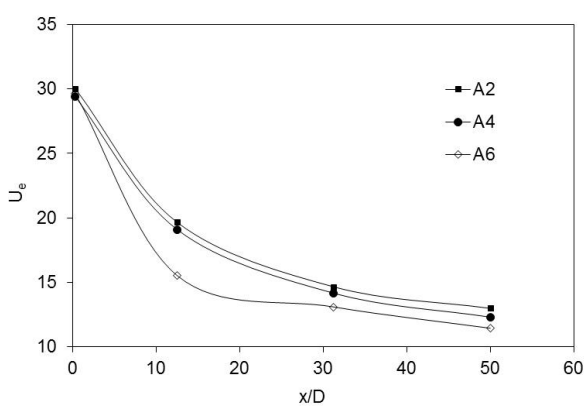

Fig. 2. Axial velocity change at tunnel velocity of $10 \mathrm{~m} / \mathrm{s}$.

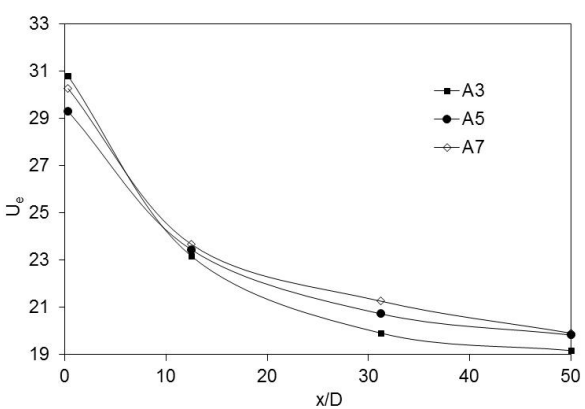

Fig. 3. Axial velocity change at tunnel velocity of $20 \mathrm{~m} / \mathrm{s}$.

When the tunnel velocity was $10 \mathrm{~m} / \mathrm{s}$ and $x / D=12.5$, the measurements show that the maximum velocity drop is in type A6 and the minimum drop is in type A2 experiment. In the other types of measurements the results are close to each other. In the measurements at $x / D=31.2$ and $x / D=50$ stations the maximum velocity drops are in types A4 and A2 experiments.

When the tunnel velocity was $20 \mathrm{~m} / \mathrm{s}$ and $x / D=12.5$, the maximum velocity drop is in type A3 and then in
A5 and A7 types. At the $x / D=31.2$ and $x / D=50$ stations, the results are the same.

Jet expansion radios, angles and jet half widths are shown in Tables II and III for the measurements at the tunnel velocities of $10 \mathrm{~m} / \mathrm{s}$ and $20 \mathrm{~m} / \mathrm{s}$. Jet expansion values calculated according to jet half widths are shown also in Fig. 4 and Fig. 5.

TABLE II

Jet expansion radios, angles and jet half widths at different stations at tunnel velocity of $10 \mathrm{~m} / \mathrm{s}$.

\begin{tabular}{c|c|c|c}
\hline \hline Code & $x / D=12.5$ & $x / D=31.2$ & $x / D=50$ \\
\hline \multicolumn{4}{c}{ Spreading ratio } \\
\hline A2 & 0.047 & 0.0223 & 0.03 \\
A4 & 0.063 & 0.0347 & 0.023 \\
A6 & 0.059 & 0.055 & 0.0293 \\
\hline \multicolumn{4}{c}{ Angles, $\left[{ }^{\circ}\right]$} \\
\hline A2 & 2.69 & 1.28 & 1.72 \\
A4 & 3.6 & 1.99 & 1.32 \\
A6 & 3.4 & 3.15 & 1.68 \\
\hline \multicolumn{4}{c}{ Jet half width $(b,[\mathrm{~m}])$} \\
\hline A2 & 0.00476 & 0.00565 & 0.01204 \\
A4 & 0.00642 & 0.00873 & 0.009241 \\
A5 & 0.0061 & 0.01389 & 0.0118
\end{tabular}

TABLE III

Jet expansion radios, angles and jet half widths at different stations at tunnel velocity of $10 \mathrm{~m} / \mathrm{s}$.

\begin{tabular}{c|c|c|c}
\hline \hline Code & $x / D=12.5$ & $x / D=31.2$ & $x / D=50$ \\
\hline \multicolumn{4}{c}{ Spreading ratio } \\
\hline A3 & 0.047 & 0.0373 & 0.0335 \\
A5 & 0.027 & 0.0396 & 0.1061 \\
A7 & 0.045 & 0.0333 & 0.0881 \\
\hline \multicolumn{4}{c}{ Angles, $\left[{ }^{\circ}\right]$} \\
\hline A3 & 2.7 & 2.14 & 1.92 \\
A5 & 1.54 & 2.27 & 6.06 \\
A7 & 1.55 & 1.91 & 5.04 \\
\hline \multicolumn{4}{c}{ Jet half width $(b,[\mathrm{~m}])$} \\
\hline A3 & 0.00479 & 0.00936 & 0.013431 \\
A5 & 0.00271 & 0.00399 & 0.042549 \\
A7 & 0.00447 & 0.00837 & 0.035283
\end{tabular}

Figures 4 and 5 show the results of jet half width measurements. Here jet half width $b$ is dimensionalized by pipe diameter $D$. In the measurements at tunnel velocity of $10 \mathrm{~m} / \mathrm{s}$, for A6 type, it is seen that the jet half width is large at the beginning but later it decreases due to the effect of the conical part on jet flow structure. It is seen that after moving away from the jet's outlet the effect of the conical part is reduced and jet half width expands again. In the A4 types it is seen that after $x / D=20$, jet expansion is similar to that of A6 type.

In the measurements at the tunnel velocity of $20 \mathrm{~m} / \mathrm{s}$ the similar behaviour, to that of A2, A4 and A6 types measurements is seen up to $x / D=10$, but later jet half width at A3 type becomes similar to that of A4. The jet 
half widths at $\mathrm{A} 5$ and $\mathrm{A} 7$ types are about 3 times bigger than the ones for the other types.

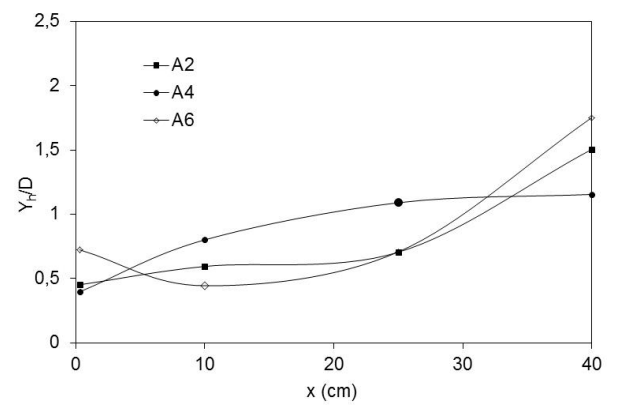

Fig. 4. Jet expansion ratios at tunnel velocity of $10 \mathrm{~m} / \mathrm{s}$.

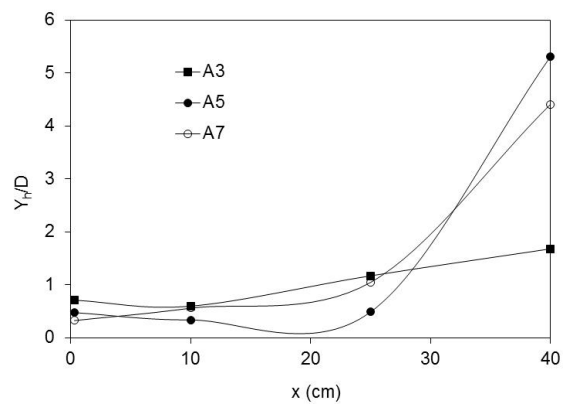

Fig. 5. Jet expansion ratios at tunnel velocity of $20 \mathrm{~m} / \mathrm{s}$.

\section{Experimental method and elements of measurement setup}

Experimental studies were done in the wind tunnel shown in Fig. 6 [18]. In the turbulence measurements hot wire anemometer (HWA) is used. 55P14-type probe is calibrated using Pitot tube. A fan of $5.5 \mathrm{~kW}$ is used to generate artificial wind in the wind tunnel. A speed control unit made the adjustment of the fan revolution speed. Air compressed by the air generator is sent to the pipe to produce the jet flow. At the inlet the pipe goes through the flow regulator, installed inside the test chamber. The conical piece supported by the flow regulator is placed at the exit of the pipe, as is shown in Fig. 7. A steel pipe with a length of $1 \mathrm{~m}$ and diameter of $8 \mathrm{~mm}$ was used for the jet flow measurements. A conical attachment having a slope of $6^{\circ}$ and $21 \mathrm{~cm}$ length was placed at the outlet of the pipe, on the same axis and at the same edge. In another experiment the outlet of the pipe was placed $2 \mathrm{~cm}$ behind the outlet of the conical piece. The connection of the air generator to the jet pipe and structure of the test chamber is seen in Fig. 8 [19].

\section{Experimental studies}

In the wind tunnel, the cross section of the entrance of the test chamber is $320 \times 320 \mathrm{~mm}^{2}$ and at the exit it is $336 \times 336 \mathrm{~mm}^{2}$. The maximum speed in the tunnel is $40 \mathrm{~m} / \mathrm{s}$ and the length of the test chamber is $75 \mathrm{~cm}$.The

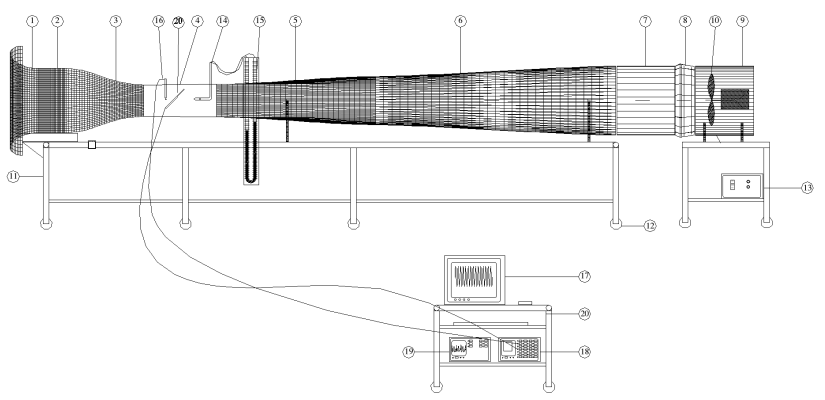

Fig. 6. Wind tunnel [18]: 1- Inlet port, 2- Resting chamber, 3- Collector, 4- Testing zone, 5- Diffusion adapter, 6-Diffuser, 7- Exit resting chamber, 8- Fan connection , 9- Fan cabin, 10- Fan, 11- Tunnel chassis, 12Tunnel carrying wheel, 13- Speed control unit, 14- Pitot tube, 15- Manometer, 16- Temperature probe, 17- Computer, 18- Hot wire anemometer unit, 19- Oscilloscope, 20- Table.



Fig. 7. Positioning of the conical piece on the jet flow pipe.

turbulence intensity in the experimental studies is $40 \%$. Hot wire anemometer with one channel is used for turbulence measurements. The calibration of the hot wire anemometer probe is made by Pitot static tube. To determine flow characteristics during turbulence measurements, spectral analysis of the velocity-time data was made and Strouhal number was found to be 0.021 .

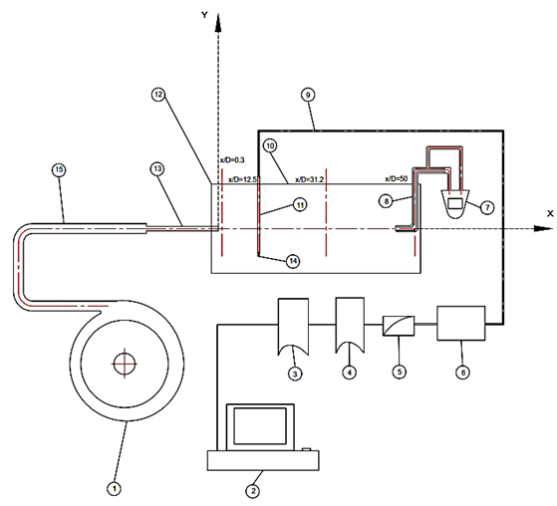

Fig. 8. Experimental Testing Scheme with Jet Air Generator [19]: 1. Jet Air Generator, 2. Computer, 3. Data analysis element, 4. Time Series, 5. Linearization, 6. Wheatstone bridge and servo amplifier, 7. Digital Pitot Static Tube Screen, 8. Pitot Tube, 9. Coaxial Cable, 10. Testing Room, 11. Probe Support, 12. Entrance of the wind tunnel testing room, 13. Jet pipe element, 14. Probe, 15. Pipe connection element. 
Experimental studies are classified in three categories:

- Circular jet measurements at different velocities without conical attachment (A1, A2, A3)

- Tunnel velocity is $10 \mathrm{~m} / \mathrm{s}$. First measurement; the outlet of the conical attachment and jet outlet are at the same level. Second measurement; jet outlet is placed $2 \mathrm{~cm}$ behind of the outlet of the conical attachment, (A4, A6).

- Tunnel velocity is $20 \mathrm{~m} / \mathrm{s}$. First measurement; the outlet of the conical attachment and jet outlet are at the same level. Second measurement; jet outlet is placed $2 \mathrm{~cm}$ behind of the outlet of the conical attachment, (A5, A7).

The data obtained after the measurements, the flow profiles, dimensionless velocity and turbulence distribution are shown in the graphs. The measurement types made in these categories are shown in Table IV.

TABLE IV

Types of measurement in the experimental studies.

\begin{tabular}{c|c|c|c|c|c|c}
\hline \hline Code & $\begin{array}{c}\text { Conical } \\
\text { flow }\end{array}$ & $\begin{array}{c}\text { Conical } \\
\text { angle }\left[{ }^{\circ}\right]\end{array}$ & Location & $\begin{array}{c}U_{j} \\
{[\mathrm{~m} / \mathrm{s}]}\end{array}$ & $\begin{array}{c}U_{t} \\
{[\mathrm{~m} / \mathrm{s}]}\end{array}$ & Fig. \\
\hline A1 & no attachm. & - & - & 30 & 0 & 9 \\
A2 & no attachm. & - & - & 30 & 10 & $10,12,13$ \\
A3 & no attachm. & - & - & 30 & 20 & $11,14,15$ \\
A4 & open & 6 & same level & 30 & 10 & 13 \\
A5 & open & 6 & same level & 30 & 20 & 14,15 \\
A6 & open & 6 & 2cm behind & 30 & 10 & 13 \\
A7 & open & 6 & 2cm behind & 30 & 20 & 14,15
\end{tabular}

\subsection{Circular jet measurements}

In order to see the effect of the conical attachments on the circular jet structure, measurement were made in three different conditions; when jet flow velocity was $30 \mathrm{~m} / \mathrm{s}$ with no tunnel flow, when tunnel velocity was $10 \mathrm{~m} / \mathrm{s}$ and $20 \mathrm{~m} / \mathrm{s}$. The results of measurements were axially symmetrical. Using the data obtained in the experiments, the distributions of dimensionless velocity were calculated and results are given in Fig. 9a, 10a and 11a. Distributions of $U_{r m s}$, indicating turbulence are given in Fig. $9 \mathrm{~b}, 10 \mathrm{~b}$ and $11 \mathrm{~b}$. Axial velocity $U_{e}$, jet half width $b$, and $R e_{D}$ and $R e_{b}$ values obtained according to the pipe diameters and jet half widths are given in Table V. Measurements are made at four stations with $x / D=0.3,12.5,31.2$ and 50 .

\subsection{Jet flow with conical attachment when tunnel velocity is $10 \mathrm{~m} / \mathrm{s}$}

When the tunnel velocity was $10 \mathrm{~m} / \mathrm{s}$ the conical attachment having a slope of $6^{\circ}$ was placed in two different positions and the measurement were made. At first, the conical attachment was placed at the outlet of the pipe on the same axis and at the same edge. Secondly, the outlet
TABLE V

Axial velocities, jet half widths and Reynolds Numbers at measurements of A1, $\mathrm{A} 2$ and $\mathrm{A} 3$ types.

\begin{tabular}{c|c|c|c|c}
\hline \hline$x / D$ & $\begin{array}{c}U_{e} \\
{[\mathrm{~m} / \mathrm{s}]}\end{array}$ & $\begin{array}{c}b \\
{[\mathrm{~m}]}\end{array}$ & $R e_{D}$ & $R e_{b}$ \\
\hline \multicolumn{5}{c}{$\mathrm{A} 1$} \\
\hline 0.3 & 29.72 & 0.00388 & 14962 & 7271 \\
12.5 & 15.46 & 0.01019 & 7783 & 9911 \\
31.2 & 8.522 & 0.02732 & 4290 & 14653 \\
60 & 6.718 & 0.04853 & 3382 & 20519 \\
\hline \multicolumn{5}{c}{$\mathrm{A} 2$} \\
\hline 0.3 & 30.04 & 0.003629 & 15305 & 6843 \\
12.5 & 19.658 & 0.004765 & 9897 & 5894 \\
31.2 & 14.655 & 0.005648 & 7378 & 5208 \\
60 & 12.976 & 0.01204 & 6532 & 9832 \\
\hline \multicolumn{5}{c}{$\mathrm{A} 3$} \\
\hline 0.3 & 30.805 & 0.00568 & 15509 & 11028 \\
12.5 & 23.172 & 0.00478 & 12667 & 6980 \\
31.2 & 19.924 & 0.00936 & 11666 & 11740 \\
60 & 19.187 & 0.01343 & 9659 & 16218
\end{tabular}


Fig. 9. Circular jet flow measurements without tunnel flow. (a) Dimensionless velocity distributions, (b) $U_{r m s}$ distributions.
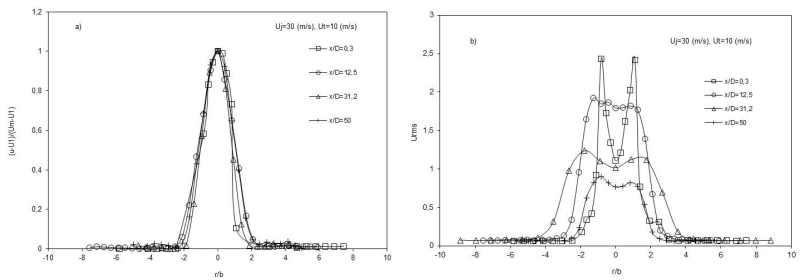

Fig. 10. Circular jet flow measurements when tunnel velocity is $10 \mathrm{~m} / \mathrm{s}$. (a) Dimensionless velocity distributions, (b) $U_{r m s}$ distributions.
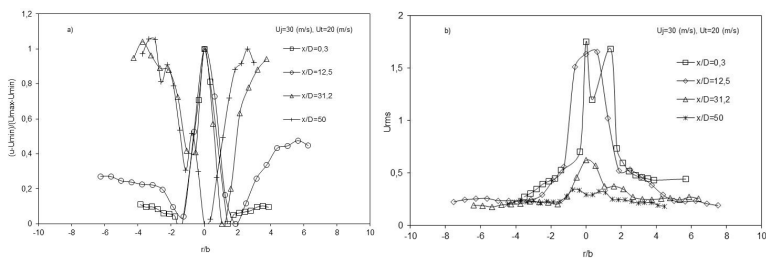

Fig. 11. Circular jet flow measurements when tunnel velocity is $20 \mathrm{~m} / \mathrm{s}$. (a) Dimensionless velocity distributions, (b) $U_{r m s}$ distributions. 
of the pipe was placed $2 \mathrm{~cm}$ behind the outlet of the conical piece. Using the data obtained during the measurements, dimensionless velocity distributions are shown in Fig. 12a for station $x / D=0.3$, in Fig. $12 \mathrm{~b}$ for station $x / D=12.5$, in Fig. $12 \mathrm{c}$ for station $x / D=31.2$ and in Fig. $12 \mathrm{~d}$ for station $x / D=50$. $U_{r m s}$ values are shown in Fig. 13a for station $x / D=0.3$, in Fig. 13b for station $x / D=12.5$, in Fig. $13 \mathrm{c}$ for station $x / D=31.2$ and in Fig. 13d for station $x / D=50$.
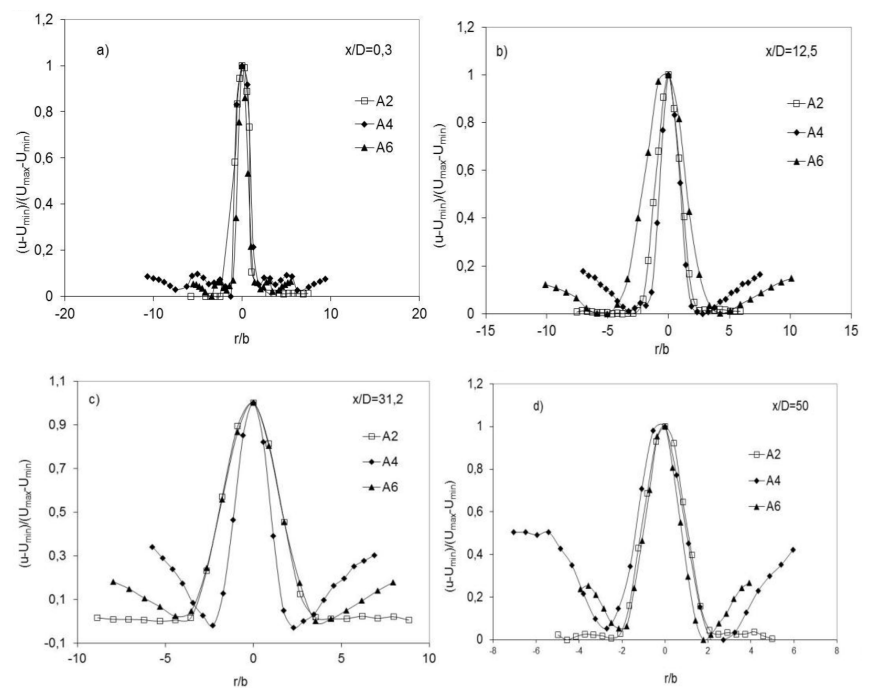

Fig. 12. Jet flow with conical attachment when tunnel velocity is $10 \mathrm{~m} / \mathrm{s}$. Dimensionless velocity distributions at station (a) $x / D=0.3$, (b) $x / D=12.5$, (c) $x / D=$ 31.2 , (d) $x / D=50$.
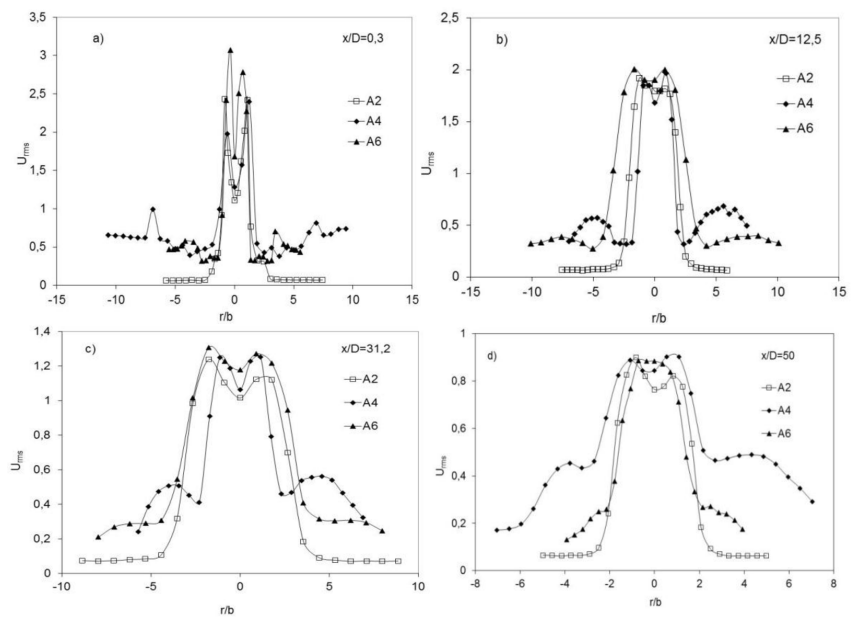

Fig. 13. Jet flow with conical attachment when tunnel velocity is $10 \mathrm{~m} / \mathrm{s}$. $U_{r m s}$ distributions at station (a) $x / D=0.3$, (b) $x / D=12.5$, (c) $x / D=31.2$, (d) $x / D=$ 50 .

Values of axial velocities $U_{e}$, jet half widths $b$, and $R e_{D}$ and $R e_{b}$ obtained according to the inner pipe diameters and jet half widths are given in Table VI. Measurements were made at four stations as $x / D=0.3,12.5$, 31.2 and 50.
TABLE VI

Axial velocities, jet half widths and Reynolds numbers at measurements of A2, A4 and A6 types.

\begin{tabular}{c|c|c|c|c}
\hline \hline$x / D$ & $\begin{array}{c}U_{e} \\
{[\mathrm{~m} / \mathrm{s}]}\end{array}$ & $\begin{array}{c}b \\
{[\mathrm{~m}]}\end{array}$ & $R e_{D}$ & $R e_{b}$ \\
\hline \multicolumn{5}{c}{$\mathrm{A} 2$} \\
\hline 0.3 & 30.04 & 0.00362 & 15305 & 6843 \\
12.5 & 19.65 & 0.00476 & 9897 & 5894 \\
31.2 & 14.65 & 0.00564 & 7378 & 5208 \\
50 & 12.97 & 0.01204 & 6532 & 9832 \\
\hline \multicolumn{5}{c}{$\mathrm{A} 4$} \\
\hline 0.3 & 29.44 & 0.003188 & 14821 & 5891 \\
12.5 & 19.09 & 0.006417 & 9613 & 7710 \\
31.2 & 14.16 & 0.008728 & 7130 & 7778 \\
50 & 12.29 & 0.009241 & 6191 & 7152 \\
\hline \multicolumn{5}{c}{$\mathrm{A} 6$} \\
\hline 0.3 & 29.63 & 0.00579 & 14917 & 10796 \\
12.5 & 15.524 & 0.00356 & 7815 & 3478 \\
31.2 & 13.092 & 0.00566 & 6591 & 4663 \\
50 & 11.436 & 0.0140 & 5757 & 10075
\end{tabular}

\subsection{Jet flow with conical attachment when tunnel velocity is $20 \mathrm{~m} / \mathrm{s}$}

When the tunnel velocity was $20 \mathrm{~m} / \mathrm{s}$ the conical attachment having a slope of $6^{\circ}$ was placed in two different positions and the measurement were made. At first, the conical attachment was placed at the outlet of the pipe on the same axis and at the same edge. Secondly, the outlet of the pipe was placed $2 \mathrm{~cm}$ behind the outlet of the conical piece. Using the data obtained during measurements, the dimensionless velocity distributions are shown in Fig. 14a for $x / D=0.3$ station, in Fig. 14b for $x / D=12.5$ station, in Fig. 14 c for $x / D=31.2$ station and in Fig. $14 \mathrm{~d}$ for $x / D=50$ station. $U_{r m s}$ values are shown in Fig. 15a for $x / D=0.3$ station, in Fig. 15b for $x / D=12.5$ station, in Fig. 15 c for $x / D=31.2$ station and in Fig. 15d for $x / D=50$ station.

Axial velocities $U_{e}$, jet half widths $b$, and $R e_{D}$ and $R e_{b}$ values obtained according to the inner pipe diameters and jet half widths are given in Table VII. Measurements were made at four stations with $x / D=0.3,12.5,31.2$ and 50 .

\section{Results and conclusions}

The experiments were made in 3 different categories and 7 types at 4 stations positioned behind the jet's outlet at $x / D=0.3,12.5,31.2$ and 50. Circular jet flow experiments at 3 types were carried out to obtain a reference before the jet flow experiments with the conical attachments. In the other cases, when the jet velocity was $30 \mathrm{~m} / \mathrm{s}$ the tunnel velocities were set to $10 \mathrm{~m} / \mathrm{s}$ and $20 \mathrm{~m} / \mathrm{s}$ at two different positions of the conical piece relative to the pipe.

At first, measurements were taken for the circular jet flow, when the maximum velocity of the jet was $30 \mathrm{~m} / \mathrm{s}$ 

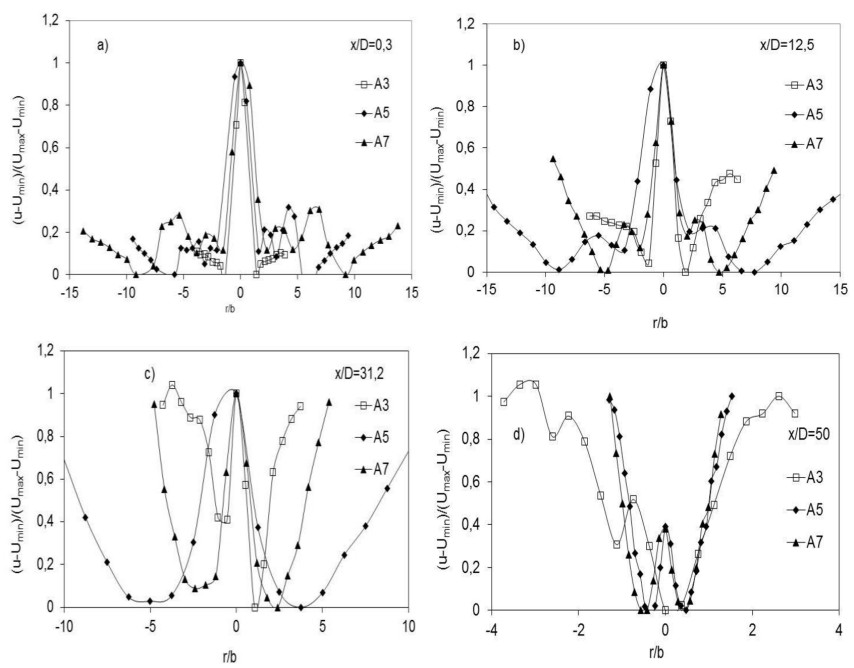

Fig. 14. Jet flow with conical attachment when tunnel velocity is $20 \mathrm{~m} / \mathrm{s}$. Dimensionless velocity distributions at station (a) $x / D=0.3$, (b) $x / D=12.5$, (c) $x / D=$ 31.2 , (d) $x / D=50$.
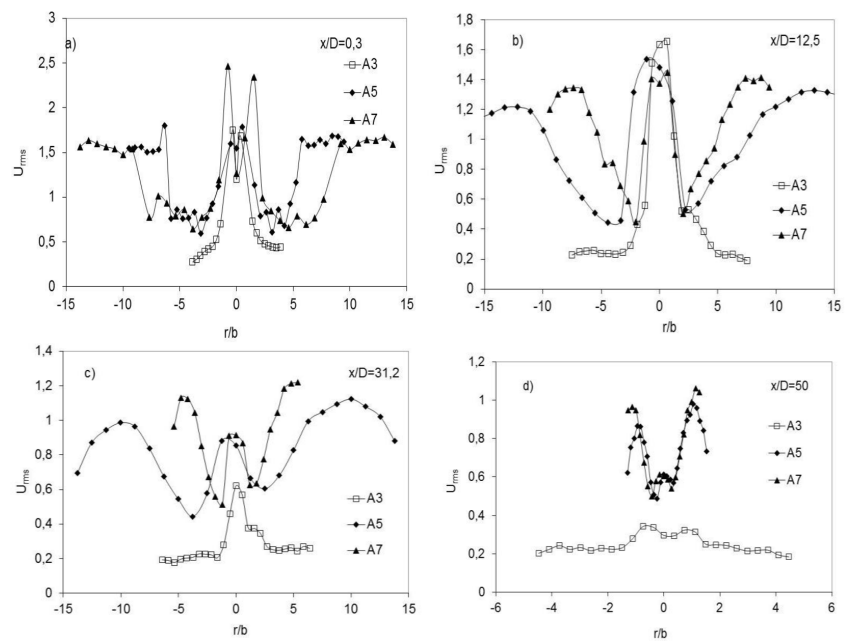

Fig. 15. Jet flow with conical attachment when tunnel velocity is $20 \mathrm{~m} / \mathrm{s}$. $U_{r m s}$ distributions at (a) $x / D=0.3$, (b) $x / D=12.5$, (c) $x / D=31.2$, (d) $x / D=50$ stations.

and without flow in the tunnel (A1). Later, measurements were taken at the tunnel velocities of $10 \mathrm{~m} / \mathrm{s}(\mathrm{A} 2)$ and $20 \mathrm{~m} / \mathrm{s}(\mathrm{A} 3)$. As the $U_{t} / U_{j}$ ratio increases the effect of the jet flow drops. When the tunnel velocity is $20 \mathrm{~m} / \mathrm{s}$ and $x / D=50$, it is seen that the effect of the jet vanishes and becomes track flow. In these categories and in all types, similar structures are seen in the turbulence distributions, however when $U_{t} / U_{j}=0.33$ the velocity and turbulence profiles are in a smoother structure. In this category it is seen that circular jet flow structures are consistent with the jet flow structures in the literature.

Secondly the measurements were made when the tunnel velocity was $10 \mathrm{~m} / \mathrm{s}$ and the jet velocity was $30 \mathrm{~m} / \mathrm{s}$. In A4 type, the conical attachment was placed at the outlet of the pipe on the same axis and at the same edge. In
TABLE VII

Axial velocities, jet half widths and Reynolds numbers at measurements of A3, A5 and A7 types.

\begin{tabular}{c|c|c|c|c}
\hline \hline$x / D$ & $\begin{array}{c}U_{e} \\
{[\mathrm{~m} / \mathrm{s}]}\end{array}$ & $\begin{array}{c}b \\
{[\mathrm{~m}]}\end{array}$ & $R e_{D}$ & $R e_{b}$ \\
\hline \multicolumn{5}{c}{$\mathrm{A} 3$} \\
\hline 0.3 & 30.8 & 0.00569 & 15509 & 11029 \\
12.5 & 23.172 & 0.00479 & 12667 & 6981 \\
31.2 & 19.924 & 0.00936 & 11666 & 11741 \\
50 & 19.187 & 0.01343 & 9659 & 16218 \\
\hline \multicolumn{5}{c}{$\mathrm{A} 5$} \\
\hline 0.3 & 29.3 & 0.003806 & 14751 & 7018 \\
12.5 & 23.446 & 0.002711 & 11804 & 4000 \\
31.2 & 20.736 & 0.00399 & 10439 & 5206 \\
50 & 19.836 & 0.042549 & 9986 & 53115 \\
\hline \multicolumn{5}{c}{$\mathrm{A} 7$} \\
\hline 0.3 & 30.27 & 0.002611 & 15239 & 4973 \\
12.5 & 23.672 & 0.004471 & 11917 & 7022 \\
31.2 & 21.273 & 0.008373 & 10710 & 11209 \\
50 & 19.917 & 0.035283 & 10027 & 44224
\end{tabular}

A6 type, the outlet of the pipe was placed $2 \mathrm{~cm}$ behind the outlet of the conical piece. In these two types four different stations were used. In the first station, at A4 type the jet half width is smaller in comparison with the one in the circular jet, and at A6 type the jet half width is bigger than the one in the circular jet. Axial velocities are slightly smaller than the ones in the circular jet. In the second station, at A2 and A4 types the axial velocities are close to each other, but they are low at type A6. Jet half widths are maximum at A4 type, then the values drops at A2 and A6 types. Jet half width at A6 type is lower than the one at the first station. In the third station, Jet half widths are maximum at A4 type and the values are the same at $\mathrm{A} 2$ and $\mathrm{A} 6$ types. Axial velocities are close to each other in the three types. In the last station, jet half widths are maximum at A6 type then the values drop at A2 and A4 types respectively. In this station, axial velocities are close to each other also. It is seen that Reynolds numbers drop from the first station up to the last station depending on the axial velocities at all types. The affect of the conical attachment on circular jet flow is seen in Fig. 12 and Fig. 13 in graphs with dimensionless velocity and $U_{r m s}$ distribution, which constitute the jet flow profile. As it is seen in the figures, the flow structures of A2, A4 and A6 types have smoother distribution than the ones of A3, A5 and A7 types.

At last, the measurements were made when the tunnel velocity was $20 \mathrm{~m} / \mathrm{s}$ and the jet velocity was $30 \mathrm{~m} / \mathrm{s}$. In A5 type, the conical attachment was placed at the outlet of the pipe at the same axis and at the same edge. In A7 type, the outlet of the pipe was placed $2 \mathrm{~cm}$ behind the outlet of the conical piece. In these two types four different stations were used. In all the measurements of this group, the maximum velocity is seen in the first station, and velocity decreases towards the other stations. Since 
$U_{t} / U_{j}$ ratio is high (0.66) the jet profiles in this group are more irregular, than the ones in the other groups, as it is seen in Fig. 13 and Fig. 14. Secondary flow velocity profiles, due to conical effect are more clear in this group and they apply pressure on the circular jet flow profile. In fact they tend to change the circular jet flow profile into trace flow profile at the last two stations. Since the $U_{r m s}$ distribution is irregular, the fact that the flow profile structure is spoiled is supported in this group also. Again it is seen in the measurements of this group that variation of the Reynolds number is small since the velocity ratio is high.

In conclusion; experimental studies of circular jet flow with and without conical attachment were done in the subsonic wind tunnel designed and made in Marmara University. Dimensionless velocity distribution, $U_{r m s}$ distribution, axial velocity drop and jet half widths obtained using the experimental data were shown in graphics and tables. The effect of the conical piece on the circular jet flow was analyzed.

\section{References}

[1] G.N. Abromovich, The Theory of Turbulent Jets, MIT press, Cambridge Mass, 1963.

[2] H. Reichardt, Gesetzmaessigkeiten der freien Turbulenz ("Similarity in Free Turbulence") 414, VDIForschungsheft (in German), 1942.

[3] S. Corrsin, N.A.C.A., Wartime Report, W4, 1946.

[4] J.O. Hinze, B.G. Van Der Hegge Zijnen, Appl. Sci. Res., Section A 1, 435 (1949).
[5] M.L. Albertson, Y.B. Jensen, H. Roose, Pro. Am. Soc. Civil Eng. 74, 175 (1950).

[6] I. Wygnanski, H. Fiedler, J. Fluid Mech. 38, 577 (1969).

[7] P.O. Davies, M.S. Fisher, Proc. Roy. Soc. A 280, 468 (1964).

[8] P. Bradshaw, Experimental fluid mechanics, Pergamon Press, 1964.

[9] H.J. Hussein, W.K. George, Proc. Seventh Symp. On Turbulent Shear Flow, Standford Univeristy, p7-30, 1989.

[10] D.B. Taulbee, S.P. Capp, H.J. Hussein, 6th Symposium on Turbulent Shear Flows, Toulouse, France, 10$5,1987$.

[11] R.A. Antonia, L.W.B. Browne, S. Rajagoplan, I. Chawbersk, J. Fluid Mech. 134, 49 (1983).

[12] S. Komori, H. Ueda, J. Fluid Mech. 152, 337 (1985).

[13] F.J. Morris, K.B.Q.M. Zaman, Journal of Sound and Vibration 329, 394 (2010).

[14] S. Sivakumar, R. Sangras, V. Raghavan, World Academy of Science, Engineering and Technology $\mathbf{6}$, (2012).

[15] W. Rodi, Ph.D. Thesis, University of London, 1972.

[16] S.P. Capp, Ph.D. Thesis, State University of Newyork at Buffalo, 1983.

[17] N.R. Panchapakeson, J.L. Lumley, Bull. Am. Phys. Soc. 31(10), (1986).

[18] A.T. Inan, Ph.D. Thesis, University of Marmara, İstanbul, Türkiye, 2002.

[19] T. Sisman, Master Thesis, University of Marmara, İstanbul, Türkiye, 2013. 